\title{
The political demography of the world system, 2000-2050
}

\author{
Paul Demeny \\ Population Council \\ Geoffrey McNicoll \\ Population Council
}

Follow this and additional works at: https://knowledgecommons.popcouncil.org/departments_sbsr-pgy

Part of the Demography, Population, and Ecology Commons, and the Political Economy Commons How does access to this work benefit you? Let us know!

\section{Recommended Citation}

Demeny, Paul and Geoffrey McNicoll. 2006. "The political demography of the world system, 2000-2050,"

Policy Research Division Working Paper no. 213. New York: Population Council. Version of record:

https://doi.org/10.1111/j.1728-4457.2006.tb00010.x 


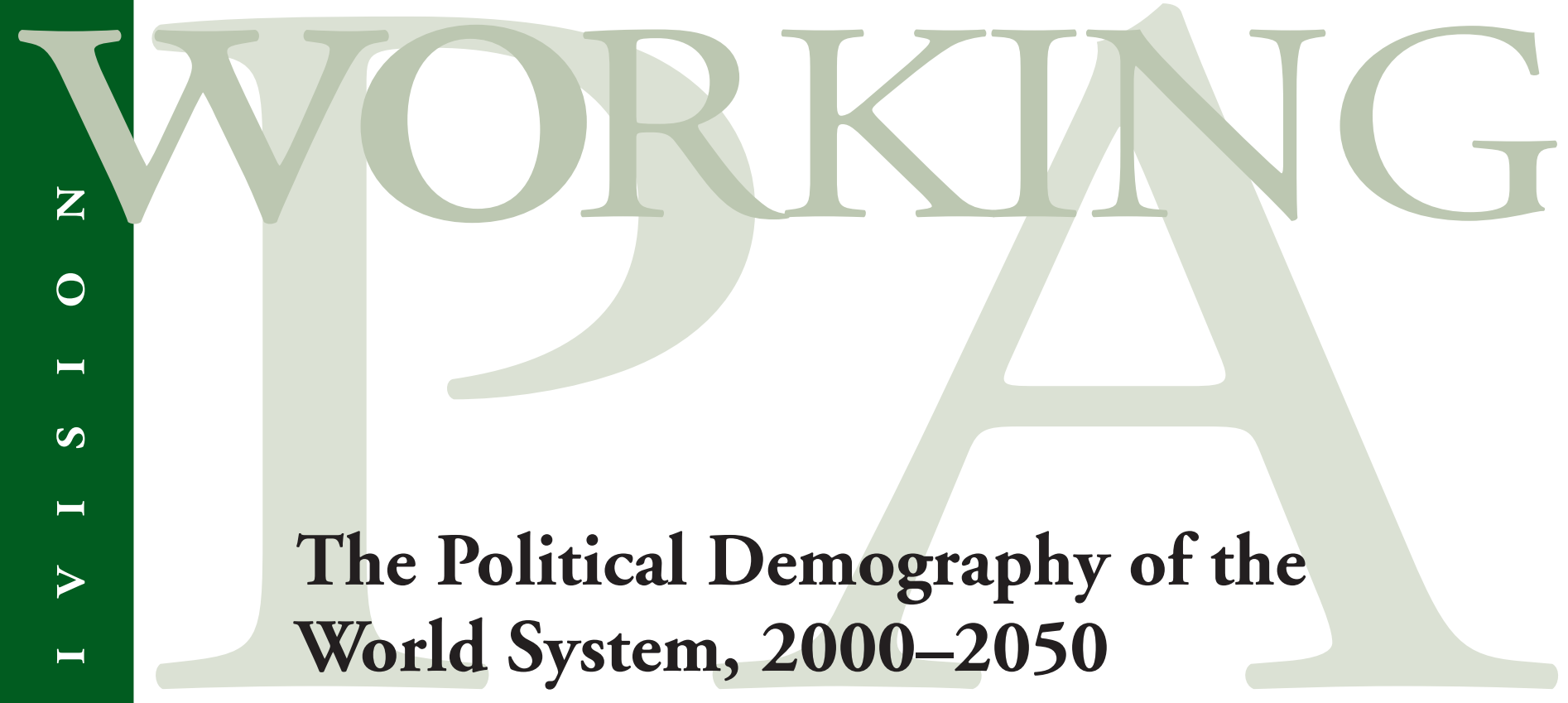

\begin{tabular}{ll} 
& \\
\hline & Paul Demeny \\
\hline & Geoffrey McNicoll
\end{tabular}

$\underline{1}$

4

2006 No. 213

[]

$\infty$

띠

$\propto$

$\nabla$

U

$\mapsto$

$\mapsto$

0

A

(2 Population Council 


\section{(P) Population Council}

One Dag Hammarskjold Plaza

New York, New York 10017 USA

www.popcouncil.org

pubinfo@popcouncil.org

This material may not be reproduced without written permission from the authors. For a list of Policy Research Division Working Papers, including those that are currently available for downloading in PDF format, see www.popcouncil.org/publications/wp/prd/rdwplist.html.

ISSN: $1554-8538$

(C) 2006 The Population Council, Inc. 


\title{
The Political Demography of the World System, 2000-2050
}

\author{
Paul Demeny
}

Geoffrey McNicoll

Paul Demeny is Distinguished Scholar, Population Council, and Editor, Population and Development Review. Geoffrey McNicoll is Senior Associate, Population Council.

Forthcoming in The Political Economy of Global Population Change, 1950-2050, Paul Demeny and Geoffrey McNicoll, editors (New York, 2006). 


\begin{abstract}
Population policies are deliberately constructed or modified institutional arrangements and/or specific programs through which governments influence, directly or indirectly, demographic change. For any given country, the aim of population policy may be narrowly construed as bringing about quantitative changes in the membership of the territorially circumscribed population under the government's jurisdiction. Governments' concern with population matters can also extend beyond the borders of their own jurisdictions. Thus, international aspects of population policy have become increasingly salient. Additions to the population are primarily the result of individual decisions concerning childbearing. Within the constraints of their social milieu, these decisions reflect an implicit calculus by parents about the private costs and benefits of children. But neither costs nor benefits of fertility are likely to be fully internal to the family: they can also impose burdens and advantages on others in the society. Such externalities, negative and positive, represent a legitimate concern for all those affected. The essay briefly discusses how individual and collective interests were reconciled in traditional societies, summarizes the population policy approaches adopted by the classic liberal state, and sketches government responses to the low-fertility demographic regime that emerged in the West between the two World Wars. In greater detail it considers international population policies after World War II and contemporary population policy responses to below-replacement fertility.
\end{abstract}


By the end of the twentieth century the bipolar competition of the Cold War had ended and the market economy model was triumphant. Economic globalization-greatly expanded international trade and capital movements, and even, to a limited extent, cross-border mobility of labor-had spread beyond the developed countries and East Asia, although very unevenly. Thus the developing world, by then four-fifths of mankind, had become far less homogeneous in both its demographic dynamics and its income per capita than it had been at midcentury. It included many middle-income countries and several emergent economic giants, all of them intent on rapid economic growth and eventual emulation of the highconsumption economies of the West and Japan. The giants-China, India, and Braziladditionally displayed nascent ambitions for regional and even global projection of influence in political, military, and cultural as well as economic domains. But the developing world also contained large regions of persistent economic backwardness and a few even of retrogression, conditions aggravated by still-rapid demographic growth. At the same time the forces of globalization had begun to create social and economic strains in the affluent countries that, in combination with aging populations, aging workforces, and incipient population decline, seemed to put in doubt the sustainability of their own gains in economic welfare and called into question the applicability of their economic success as a model for the rest of the world.

The social sciences offer no means of forecasting the evolution of this global economic and political system over the next half-century - not even of distinguishing, among the plausible drivers of change, those that will in retrospect be judged the most significant. Recall how little of the world of 2000 was foreseen in 1950. But while steering clear of prediction, we can at least lay out some of the trends that are underway and explore their implications. Moreover, in comparison to some other efforts at future-gazing, we can call on the relatively robust structural frame that demography supplies. Compared to the rate of turnover and obsolescence in physical capital and technology, people are long lived. Some 40 percent of the population of 2050 (and probably about the same proportion of the labor force) is already alive in 2005-whereas much of the technology and a large part of the capital stock of the economy in use in 2050 have yet to be created. Moreover, mortality and fertility also tend to change in fairly predictable ways with industrialization and urbanization, giving some assurance to population forecasts at least over the next several decades. (Based on past experience, uncertainties mount up rapidly thereafter.)

\section{POPUlATION AND ECONOMY: FORECASTS TO 2050}

The near-worldwide decline of fertility over the second half of the twentieth century has taken the "population problem" off the agenda of international relations. That relegation is unfortunate. It misconstrues the likely role of the demographic factor in the world system during the coming decades.

The United Nations estimates for 2000-05 put the average total fertility rate (TFR) for

the more developed countries at 1.6 children per woman, and for the less developed world at 2.9. There are large contrasts in age distributions between regions-still relatively youth- 
ful in the less developed regions, exhibiting advanced population aging in the developed world-reflecting the timing and pattern of past fertility and mortality declines. The medium UN projections envisage gradual convergence in demographic behavior and eventually also in age distributions. Over the coming decades, however, this convergence will not prevent continuing large shifts in relative population sizes between regions and among major countries.

The same UN projections foresee global population growth between 2005 and 2050 of 2.6 billion - a net increase larger than the total world population in 1950. That increase is distributed highly unevenly across world regions. Holding constant the categories of "more" and "less" developed (admittedly, labels that have become increasingly vacuous ${ }^{1}$ ), the population of the more developed regions is projected to grow by only 25 million. This is despite the assumption that net immigration into those regions will amount to 98 million during the 45-year period. Thus, 99 percent of the global growth is expected to occur in the less developed regions.

Among major regions, Europe (including Russia) shows the most pronounced loss in terms of relative size. Its population was 22 percent of the world's total in 1950. By 2005 that figure had fallen to 11 percent. In 2050 it is expected to be 7 percent. In absolute terms, Europe's population is estimated to be 728 million in 2005. Despite an assumed net immigration of 32 million persons during the next 45 years, a further improvement in its mortality, and a recovery of its fertility from the current TFR of 1.4 to 1.85 by midcentury, the continent's population would fall to 653 million in 2050 - that is, 75 million below its present level.

At the other regional extreme, Africa's population is projected to continue its rapid growth. Africa's share of global population was 9 percent in 1950, increasing to 14 percent in 2005. It will be 21 percent in 2050. Its projected absolute population growth during the next 45 years is more than 1 billion.

Table 1 sets out the anticipated growth in the first half of the twenty-first century against the previous half-century for major countries and regions. The spacings in the table loosely delineate three North-South segments of the globe. Africa and Western Asia are reconfigured into sub-Saharan Africa (as the UN defines it) and a group of countries termed the "Muslim tier"--significant in this study especially as a major source of immigrants to Europe. $^{2}$

This differentiated pattern of demographic expansion yields a new clutch of heavyweight countries in the world. Arbitrarily identifying these as countries with populations above 100 million, the picture given by the UN estimates for 2005 and medium-variant projections for 2050 is shown in Table 2. Some rearranging of the list takes place over this period, with India overtaking China, and Pakistan and Nigeria moving up in the size ranking. No country is forecast to drop out of the list in this period, but Japan and Russia are not far from doing so. Emerging demographic heavyweights are Congo, Ethiopia, Philippines, Uganda, Egypt, Viet Nam, Iran, and Turkey. (Astonishingly—and implausibly—-these projections place Afghanistan barely lower, reaching 97 million by 2050.)

No European Union member country appears in Table 2. However, if the EU with its current composition (EU-25) is taken as constituting a state-like entity, it would appear with a 
population of 460 million in 2005 — third, after India and ahead of the US — and 450 million in 2050 - still third, but by then some 20 million below its peak and within range of a stillgrowing United States. Of course, the EU may have expanded further by midcentury: accession of Turkey, should it occur, would alone raise its 2050 population by nearly one-quarter.

Such population figures take on a fuller meaning in combination with current economic conditions and their plausible future evolution. If so considered, they suggest a major gain in the coming decades in the economic weight and thence the geopolitical importance of the Asia-Pacific region and of South Asia, in comparison to the North Atlanticthe region which, at least for the last two centuries, has held a preeminent position in the global hierarchy of economic and military power, scientific and technological prowess, and cultural influence. China, and at a farther distance also India, may soon rival the United States in gross domestic product. For example, in recent forecasts by Goldman Sachs, China's GDP exceeds that of the United States around 2040, India's a few decades later. At purchasing power parity, by 2001 China's economy was already three-fifths the size of that of the United States, India's one-quarter. (In comparison, in that year by the same measure, Latin America's economy was 39 percent of that of the United States, Africa's 15 percent.) ${ }^{3}$

Major per capita income differentials between currently rich and poor countries will, however, persist. Continued faster economic growth in per capita terms in the less developed world in comparison to the rich countries - the broad experience of recent decades, though with important exceptions-must eventually close that income gap, but even under the most daring assumptions in most instances this process will be far from completed by midcentury. In the Goldman Sachs forecasts just cited, China in 2050 would have a per capita income roughly equal to the average of the developed world around the turn of the millennium. In the early phases of the catch-up process, of course, it is virtually an arithmetic certainty that absolute per capita income differentials between countries will further widen.

Finally, the staggered pacing of demographic transition among world regions is reflected in a remarkable variation in the forecast levels and rates of increase in the proportions of youth and the elderly (see Table 3). Provision of old-age support, private or public, has mainly entailed pay-as-you-go transfers from workers or taxpayers to retirees. The figures in Table 3 signal the increasing fragility of that mechanism as the proportions of the young and the old move in opposite directions. The order shown in the table corresponds to the comparative stage in the aging process: Japan and the EU in the vanguard, Africa bringing up the rear. China, with its precipitous fertility decline in the 1970s and 1980s, is two or three decades ahead of India.

Long-range forecasts of dependency ratios - as defined in demographic terms ${ }^{4}$ - are sensitive to assumptions about fertility and longevity (especially life expectancy at older ages), both of which are straddled by substantial confidence intervals. (Levels of immigration also affect dependency, but, as noted below, not by much at the ranges that are likely to be politically acceptable to countries of immigration.) A fertility recovery that yielded family sizes nearer two than one is not impossible in Europe and Japan, albeit unlikely in the view of many observers. The course of mortality at older ages in the developed world is even more uncertain - a further consequential matter for the financial condition of pension funds. The nearing approach of high old-age dependency combined with these uncertainties pushes gov- 
ernments toward adoption of retirement schemes involving individual retirement accounts, in which savings and later dissavings take place over each person's life cycle. ${ }^{5}$

\section{MigRATION AND IDENTITY}

Income differentials, in combination with relative population sizes and rates of increase, clearly point to the continuation and the likely intensification of migratory pressures, with the potential to generate massive population movements from poor to rich countries. To what extent such movements actually materialize is a different matter. Migrantreceiving countries seldom plan the number of migrants to be admitted beyond the next few years - and where plans do exist, they can be and are revised at will or altered by circumstance. The migration assumptions incorporated in the UN projections, such as those cited above, are arbitrary, hence purely illustrative. They typically assume, country-by-country, continuation of the volume of the migrant stream estimated for the most recent past, or at a somewhat reduced level. The actual number of migrants may turn out to be far greater than this. Mexican migration into the United States in the 1950s and 1960s, for example, poorly signaled the massive influx from Mexico in more recent decades.

Migration may also turn out to be smaller than simple extrapolations suggest. Public opinion in the main receiving countries, especially in Europe and more specifically in the European Union, has, on balance, increasingly favored less migration - a sentiment reinforced by recently heightened tensions surrounding Europe's Muslim minority and by the volume of unskilled migration into the United States. Strict enforcement of the rules adopted in this sphere could greatly restrict migration flows, both legal and clandestine. Yet enforcement is costly in economic terms and infringes on other values and preferences of the native population. Moreover, in every immigrant-receiving country there are numerous persons and interest groups strongly favoring relaxation of rules in particular cases or for particular types of immigrants: their wishes often prevail over the weakly expressed preferences of the greater number of those favoring tighter restrictions.

Such differences in attitude are typically strongly correlated with position in the income or class hierarchy. Whether in their private capacity or as entrepreneurs, more affluent segments of the population disproportionately benefit from greater access to low-wage domestic service workers or to wage laborers willing to work for wages below the rates that native workers would demand. At the same time, wealthier persons are apt to have less exposure to situations that may be seen by many as discomforting, such as the changing ethnic make-up in residential areas or in the schools their children attend. Persons in lower income classes bear the brunt of such exposure.

An often-repeated argument favoring immigration invokes the economic and social problems associated with population aging and the "needs" of the labor force. The influx of migrants, it is held, rejuvenates the age structure and fills jobs that otherwise would go unfilled. Migrants, if employed, thus ease labor force adjustments and prop up the pension and health care systems of the receiving country. But as demographers know, this, at best, is a temporary remedy for population aging. Immigrants also age; they eventually cease to be workers and taxpayers and become claimants on pensions and other entitlements. To main- 
tain the rejuvenating effect would require sustained immigration on a scale that over time would radically change the numerical balance between natives and immigrants- $\mathrm{a}$ transformation unlikely to be welcomed by most persons in the receiving country. That transformation-David Coleman calls it the third demographic transition-is accentuated where native-immigrant cultural differences are large and migrant acculturation to the mainstream is slow. Cases in point are European cities like Rotterdam and Birmingham.

Within broad limits, modern industrial societies should be able to cope with the economic and social problems caused by population aging without recourse to immigration. The institutional changes required for that purpose are well known. The availability of an apparently "easier" solution for those problems, through immigration, allows societies to avoid the needed reforms - as well as to avoid thinking seriously about policies to encourage higher birth rates.

In filling labor force needs, the advantages and disadvantages of immigration would have to be compared to alternative means of adjustment, whether policy-induced or arising in response to market signals: mobilizing labor reserves from the native population; developing and adopting technologies that substitute for labor; upgrading wage rates to elicit labor supply responses; and, not least, eliminating activities that could only be sustained with low-wage labor. Each of these adjustments, whether applied separately or in combination, has its costs. Over time these costs may, however, prove to be lower than those entailed in the reflexive reliance on immigration.

The migration solution looks easy because of the magnitude of the supply pool of potential migrants - a function of income differentials and relative population sizes. ${ }^{6} \mathrm{Al}-$ though geographic proximity now has less influence on migration decisions than in the past, when transportation and communication costs were higher, the point may be illustrated by comparing migrant-receiving countries with potential sender countries in the same general geographic neighborhood.

The European Union provides the principal case in point. (The North American case is similar in many respects, apart from its higher native-born fertility levels and its more flexible labor market.) Consider the three EU countries with the largest net immigrationGermany, Britain, and Italy — and the three largest potential migrant suppliers in the EU's "southern neighborhood"-Egypt, Turkey, and Iran. In 2005, the comparative population sizes of each group are almost the same: 204 million in the three EU countries, 217 million in the three countries of the southern neighborhood. For the next 45 years, the UN assumes net immigration of 9 million into Germany, 6 million into Britain, and over 5 million into Italy and substantial, although less massive, emigration from Egypt, Turkey, and Iran. Nonetheless, the medium projections for 2050 show a major shift in comparative population size: a slight decline, to 197 million, in the three EU countries, but a 50 percent rise, to 329 million, in the southern three. ${ }^{7}$ Per capita income (2002 estimates in purchasing power parity terms) was above US $\$ 25,000$ in each of the three EU countries; it was about $\$ 6,000$ in Turkey and Iran and less than $\$ 4,000$ in Egypt.

Vastly greater pools of would-be EU migrants exist in other parts of Africa and West Asia. Indeed this whole region might, somewhat provocatively, be called Europe's "southern hinterland." Its relative size contrasted with the EU itself, past and projected, is shown 
in Figure 1. Clearly, there is the potential for immigration into the EU on a much larger scale than is assumed in the UN projections. The same is true for other high-income areas, not only the traditional immigration countries—United States, Canada, and Australia—but also Japan and other prosperous East Asian countries and perhaps some emerging Latin American countries such as Brazil. More to the point, the potential flows are larger too than envisaged by any of the migrant-receiving countries. Should such flows materialize, they would amount to only a modest downward correction to population growth trends in the sending countries but could radically change the demographic make-up of the receiving countries. Both historical experience and present-day indications suggest that such changes can have unwelcome consequences — cultural, economic, and political — whenever assimilation of migrants proves to be difficult, whether because of attitudes prevailing in the receiving society or attitudes of the migrants themselves.

The right to determine who is admitted as a migrant is fundamental to the modern state system. In practice, as suggested above, the complex mixture of gains and losses that are entailed and the interplay of interest groups with stakes in the outcome make the decisionmaking process inherently difficult. Moreover, sending countries may also claim a stakethrough their concern for relieving domestic unemployment, for the well-being of their expatriate citizens, and, more tangibly, for the remittance flows that may be generated. This spread of claims has suggested to some a case for international regulation of migration. In the 1920s, Albert Thomas, then director of the International Labour Office, asked whether the time had come "for considering the possibility of establishing some sort of supreme supranational authority which would regulate the distribution of population on rational and impartial lines, by controlling and directing migration movements and deciding on the opening-up or closing of countries to particular streams of immigration" (Thomas 1927). Such ideas resurface in contemporary policy discussions in the international arena-for instance, Kofi Annan's remark in a 2004 speech that "migration is an issue that demands greater international cooperationnorms and policies to manage migration in the interest of all." ${ }^{8}$ While any move toward sharing policymaking responsibility with sending states would no doubt be resisted by the receiving states, the issue introduces an additional level of uncertainty in forecasting the volume and direction of international migration in the coming decades.

For temporary labor migration, joint decisionmaking is certainly to be expected. Such schemes, bringing in migrants on work contracts for a fixed period, could be established to the mutual benefit of the receiving and the sending countries (justifying a quid-pro-quo in the form of material compensation for the sender), and, of course, of the migrants themselves. Although there are successful models for such guestworker arrangements, their potentials have not been much explored. An expansion of temporary migration, skilled and unskilled, has been under consideration in the United States in response to employer pressures and, in the unskilled case, as an offset to more stringent border controls. Such schemes should be of particular interest to countries in which popular sentiment is unequivocally against permanent immigration, such as Japan. Short of draconian administration, full enforcement of the return provision for guestworkers (presumably to be replaced by new recruits) is not to be expected, but that goal is not necessarily a condition for success pro- 
vided return rates can be kept high. A side benefit of such a scheme could be its use in selecting participants to be offered permanent residence.

Migration within the countries of the European Union presents a special case of international migration. The label "international" is warranted, as EU countries retain major elements of national sovereignty. Treaties guarantee citizens of member countries the right to free movement, for whatever purpose, within the Union. (Labor migration from countries that joined most recently is subject to temporary restrictions by some members of the EU-15.) Through the Schengen agreement, involving a large subset of the continental EU countries, the right to free movement and settlement is also guaranteed to persons to whom any Schengen member country has granted permanent immigrant status. When differentials in income are minor, as in the case of the EU-15 countries, labor migration is likely to be small, an outcome reinforced by cultural and linguistic barriers. Few persons from Munich wish to take up work in Lyon, and vice versa. Labor migration from the rest of what is now the EU-25 has greater potential, evidenced by the labor inflow to Britain and Ireland (especially from Poland). But the most important migration type within the EU in the coming decades may turn out to be retirement migration-retirees attracted to parts of Spain, for example, in a pattern similar to that observed in Florida or Arizona in the United States.

Outside the EU, while free trade agreements have proliferated, the more radical integration involving common markets for labor has been rare. Australia and New Zealand have such an arrangement. Some regional groupings — notably ASEAN—have at times contemplated doing so. ${ }^{9}$ The North American Free Trade Agreement, in contrast, has deliberately refrained from promotion of cross-border labor mobility-indeed NAFTA was originally seen by some as a kind of bulwark against unregulated inflows to the United States and Canada. A fortiori that would be true of any extension further southward, as in the Central American Free Trade Agreement or the bruited Free Trade Agreement of the Americas (FTAA). In practice, as noted earlier, regulatory efforts to curtail migration reflect the diversity of economic and political interests in the matter, typically combining fairly strong if less than effective border controls with lax enforcement of employer sanctions.

This discussion is necessarily inconclusive, but it clearly suggests that migration flows from less developed countries to the rich countries during the next half-century-especially to North America and the European Union — will be at least as large as and possibly significantly larger than those observed in recent decades. At the same time, it seems probable that receiving countries will raise their expectations of migrant cultural assimilation and adopt more stringent control and surveillance measures (border security and registration or ID requirements), in part in response to xenophobic and nativist reactions by their citizenries. These measures notwithstanding, by midcentury both of these continent-size areas are likely to have populations far more varied by ethnic and cultural background and by geographic origin than they were at the turn of the millennium.

\section{Fraying Sovereignty: Fission And CoAlescence}

Countries are creations of history: their continuity over time is not carved in stone. They can split into smaller units or merge to form larger entities. The post-World War II 
period brought a proliferation of national units. This was largely the result of the dismantling of the colonial empires, the last phase of which was completed with the gaining of independence by the 15 former republics of the Soviet Union. Disintegration of some artificial national constructs contributed to the process, such as the separation of Bangladesh from Pakistan, Singapore from the Malay Federation, Eritrea from Ethiopia, and the split of the former Czechoslovakia and Yugoslavia into their major constituent units. The division of Korea into two separate states solidified after the 1953 armistice. Southern Sudan is promised a future opportunity to break from the country's Arab north.

It is possible to see this pattern as the triumph of atavistic nationalist hatreds over the economic logic of market size, but closer examination tends to reveal the continued relevance of economic motives. Often the impulse to secede comes from an economically successful or fortuitously resource-rich subregion of a country, seeking to preserve or enhance its position by erecting barriers to entry. ${ }^{10}$ The lessons of the economics of German reunification are read as proving the merits of disunity in rich South Korea; the economic success of Hong Kong holds a lesson for Shanghai as well as for China's several eastern provinces.

Subnational devolution of political power, short of national independence, is also in evidence, potentially offering the devolved entity greater economic returns (perhaps concealed in nationalistic rhetoric) while remaining under the security umbrella of the state. Quebec is an example, as are, in Europe, Scotland, Wales, Catalonia, Corsica, Wallonia, and Flanders. Far-reaching regional autonomy was built into the postwar reconstruction of Germany as a federal republic, and devolution by legislative reform gave greater powers to regions in France and Italy. Striving for movement in similar directions has been evident in many other countries as well, illustrated by the examples of Nigeria, Indonesia, Philippines, and Sri Lanka.

Is the present configuration of states approaching some near-permanent form or will the process of fission continue indefinitely? Working against further change is the entrenchment of the principle of national sovereignty in the United Nations Charter and in the everyday workings of international institutions. Efforts to override it by acknowledging a right to self-determination for some aspiring national entity (self-determination is also a UN principle) — or even to protect human rights in the face of egregious government violationshave been rare. A few states-perhaps Iraq included-may yet hive off separate nations; Russia could shed some troublesome Muslim territories along its southern borders. Ascendant powers, however, encounter few challenges in dealing as they please with minor wouldbe states on their fringes, such as Sikkim or Tibet.

The reverse phenomenon to fission - the consolidation of multiple political units into one-has seen few examples in the past 60 years. The most notable is the merger of the former East Germany into the Federal Republic. And of signal importance, although not classifiable under the traditional category of independent statehood, is the creation of the European Union. Starting with the six-country association under the 1957 Treaty of Rome, by 2004 the EU encompassed 25 states, with a population of 457 million, pledged to form "an ever closer union." "11 Member states preserve essential elements of sovereignty but cede by treaty many former state functions to a common, nonterritorial, political machinery head- 
quartered in Brussels. Whether it should espouse more thoroughgoing federalist ambitions or settle for the less radical "Anglo-Saxon" confederate model remains a matter of disagreement among the member states, with far from predictable resolution.

East Asia has a number of efforts at regional integration. ASEAN, now including all Southeast Asian states except East Timor, is well established, seen by some as eventually growing into an EU-style entity. Institutional thickening can be measured in the continual invention of new ties among member governments, the progressive easing of bureaucratic barriers, and the profusion of meetings, dialogues, and working groups. There is no Brussels in view, however, let alone a regional parliament. It remains more an intergovernmental organization than a superstate manqué.

Integration across East Asia as a whole has not progressed as far but may have greater prospects. A Japan-centered East Asian economic system seemed in the cards in the 1970s and 1980s, with massive Japanese investments in the region creating a set of burgeoning economies following in Japan's train. (Lingering memories of Japan's colonial and wartime interventions precluded such relationships extending much beyond the economic.) But then came the dramatic slowing of Japan's economy in the 1990s, coinciding with China's economic take-off fueled by the rapid strengthening of the investment and production networks of "greater China" (China, Taiwan, and Hong Kong). By the end of the century it was apparent that any emerging East Asia-wide economic system would be centered on China, not Japan. ${ }^{12}$ A plausible institutional framework for an East Asian community is the grouping known as ASEAN Plus Three (APT), adding China, Japan, and South Korea to the ten ASEAN states.

Moves toward regional coalescence, at least in the economic sphere, are also seen in the other major world regions. SAARC (South Asian Association for Regional Cooperation) formally brings together all South Asian states, though it could also be seen as defining India's hegemonic reach-aside from Pakistan's sometimes awkward inclusion and potential role as spoiler. But India's rapidly increasing economic strength and place as an emerging world power arguably gain little from that grouping.

Latin America south of Mexico, once to be accommodated by NAFTA's transformation into the Americas-wide FTAA, is now more often seen as an emerging region in itself, building on its two main existing trade pacts, Mercosur and the Andean Community. An envisaged continent-wide South American Community of Nations (CSN) would be explicitly modeled on the EU-even to a common passport and currency. Brazil is set to remain the region's heavyweight power: its GDP in 2004 was four times the size of Argentina's, the next largest economy (though not yet surpassing Mexico's). In the Goldman Sachs forecasts, it would be closing on Japan's GDP by $2050 .{ }^{13}$

The Middle East and North Africa, from the Maghreb to the Gulf, has a loose political identity in the 22-country Arab League and has displayed sporadic aspirations to unity. There is substantial labor migration within this region but little basis for a strong regional economy. Finally, the African Union-successor to the Organization for African Unityhas a broad integrative ambition, if as yet with scant accomplishment. In the words of the African Union Commission (2004: 16), “Africa must form vast and viable internal markets 
to...pave the way for inter-African division of labour according to relative domestic and external advantages, and confer on these huge collective entities a genuine power of negotiation with the markets already constituted on other continents."

The present and projected population sizes of the main regional groupings are shown in Table 4. Together these now make up 88 percent of the world population, a proportion that would be maintained in 2050 under the assumption of unchanged country composition. Market size, of course, would yield a different ranking, with the EU and NAFTA currently well ahead but ASEAN Plus Three rapidly catching up and SAARC also becoming a major market force.

The more general change that permits moves toward "ever closer union" in regional groupings, but that extends beyond regionalism, is a shift in the meaning of national sovereignty itself. Such a change is signaled by the popularity of adjectives like virtual or postmodern to describe certain countries. The "virtual state," analogous to the virtual corporation - a company "with a head but no body" - supplants the older trading state that was obsessed with territory and resources and worried about locating production within its borders (see Rosecrance 1996). Japan, Korea, and Singapore are in the vanguard of virtuality; China and Russia remain "territorial fetishists" (ibid.). Postmodernity as a political characterization appears in the work of international relations theorists like Buzan (1998) and Cooper (2003), who divide countries into premodern, modern, and postmodern. The modern group is made up of the conventionally-sovereign states that first emerged in seventeenth-century Europe and gradually became a universal model of statehood, spreading worldwide with the ending of the colonial empires. The premodern countries are the Somalias, Afghanistans, Sudans, and Liberias - characterized by "low levels of sociopolitical cohesion and poorly developed structures of government" (Buzan 1998: 223), whether not yet having reached modernity or having degenerated into political disorder and ungovernability. And the postmodern are those that have begun to relax their sovereignty. "Postmodern states have a much more open and tolerant attitude toward cultural, economic, and political interaction, and define a much narrower range of things as threats to national sovereignty" (ibid.: 221-222).

The postmodern world is the one taking shape in Europe, envisaged in the treaties underpinning the European Union ("a highly developed system for mutual interference in each other's domestic affairs, right down to beer and sausages"-Cooper 2003: 27), the Council of Europe, and the Organization for Security and Co-operation in Europe, with glimmers of a wider application indicated by a slew of international treaties on matters such as security, justice, and the environment. America, in this classification, is in many respects still a "modern" state, its concessions to internationalism (principally the WTO) often reluctant and subordinated, when deemed necessary, to national interests. In East Asia, China is modern, Japan postmodern.

Is postmodernity, in this political sense, the all-but-inevitable path for the world as a whole as globalization proceeds, or a fairly special outcome among a few groups of likeminded states? Consideration of demographic realities, undertaken below, would suggest the latter is the more likely. 


\section{DEMOGRAPHY AND GLOBALIZATION}

The large income differences that drive contemporary international migration are the results of a long process of uneven development. In a stylized depiction of economic history, each country journeys from a position of poverty along a path toward greater material comfort. Some countries progress rapidly, others lag behind. The speed of advance is not uniform: overtaking and backsliding occur, gaps between countries narrow or widen. At least since the industrial revolution, however, Europe and its overseas offshoots, notably the United States, along with Japan, have led the pack. Their lead increased considerably over the last century.

The factors explaining the economic ranking at any moment are complex, intertwined, and often deeply rooted in the past. Among them are differences in acquisitiveness and in aptitude in seeking material advancement; ability to develop institutions conducive to thrift, trust, and cooperation beyond kin groups; interest in science and in its practical applications; favorable geographic location, climate, and access to natural resources; military prowess and skills in making and maintaining peace; and willingness to take risks and luck in having them pay off. A host of others could be added.

One of these factors, again in interaction with others, is demographic behavior. During their modern history, the presently rich countries benefited from the economic stimulus of spurts in population growth, yet they avoided the kind of expansion that, by natural increase alone, can multiply a population eightfold or more during a single century. Europe, in particular, could have built up a population that today would be a numerical match to China or India, or that could even have surpassed those countries in size. But, under the guidance of fortuitous institutional structures, Europe's aggregate population growth was kept in check during its modern history. By the late twentieth century, under circumstances of unparalleled prosperity, Europe was approaching zero population growth. Its countries developed elaborate welfare states, promising, and to a large extent providing, material comforts and security to every citizen. Europe seemed prepared to settle down to enjoy the pleasures of a stationary state.

Europe's offshoots in North America and Oceania retained much the same demographic pattern of moderate to low natural increase (births minus deaths). Their distinctiveness lay in tolerating and even promoting a large migrant influx, accommodated initially by an open land frontier and subsequently by similarly open labor markets-and, in the US case especially, more modest provision of an economic safety net.

Being born in one of these rich, stable societies in effect automatically imparts a giftan unearned rent traceable to the wise demographic choices, individually or in their aggregate result, made by ancestors in a parade of generations reaching back into the deep past. Those seeking entry into these lucky countries by immigration can be thought of as trying to capture that same rent by the only other available route.

\section{Threats to the European social model}

Ironically, even before being fully able to realize its promises, this "European social model" - both in Europe and in its counterparts elsewhere-is now under threat. It is menaced from two developments, each of which has a key demographic component. 
The first of these threats is overshoot in the reduction of fertility. Bringing fertility to a long-run replacement level is a historical imperative. Falling somewhat under replacement need not be differently characterized: fertility cannot be fine-tuned to 2.06 children per woman. For a long period, affluent industrial societies could certainly live with a slow decline in their populations and adjust to the economically less advantageous age structure associated with it, without suffering grim economic and social consequences. But should fertility settle at a level deeply below replacement, the rapid fall-off in population numbers together with the associated age structure-resembling, if plotted as an age pyramid, a pear stood on its stem - cannot be accommodated. Short of a policy-engineered revival of fertility, which, of course, has a long (20 years plus) lead time, mass immigration then becomes the only possible remedy. The scale of migration called for, however, elicits the kinds of responses discussed earlier in this chapter. Not least among them would be the erosion of political support for the redistributive measures of the welfare state.

The second population-linked threat is external: it arises from the processes of globalization, which draw mature postindustrial, post-demographic transition societies into economic interaction with materially much poorer societies-societies that have a different demographic past, different current demographic configurations, and different demographic prospects.

Economic theory supplies a convincing demonstration of the advantages of extending the scope of economic interactions from the narrowly local to the national and, beyond that, to the global level. Although the demonstration is studded with massive ceteris paribus assumptions that dictate caution, it is evident that larger markets permit greater division of labor, stimulate competition, specialization, innovation, and higher productivity, and provide their participants with access to a greater variety of goods. In so doing, the enlarged market delivers higher incomes and promotes economic growth: it makes individuals and countries richer.

Historical experience bears out the thesis. The first great epoch of globalization, the late nineteenth and early twentieth century, brought rapid economic growth in the leading industrial countries and sparked the beginning of industrialism throughout the rest of the world. The drastic curtailment of international trade by protectionist policies in the interwar years was associated with low growth and eventually with the misery of the Great Depression. After World War II, renewed efforts at international liberalization resulted in a vast expansion of international trade and unprecedented prosperity.

But that postwar success story was, in fact, geographically quite limited, and hence is a less than compelling argument for the merits of globalization. Much of the expansion of trade took place among the rich countries. These countries possessed similar or fast-converging levels of income, rendering them natural partners in trade. The second world-the Soviet Empire, with China nominally also included-was not part of the emerging free trade zone. Neither was India, an official admirer and would-be imitator of the Soviet prewar ambition of "socialism in one country." The countries of Africa mostly espoused and in part practiced "African socialism," and those of the Middle East similarly experimented with local varieties of the socialist model. Ideology also kept much of Latin America out- 
side the revived world market: interaction with the "center" was seen as perpetuating peripheral status and solidifying economic dependency.

The conspicuous exceptions to these stand-apart regions were the market-oriented countries of East Asia. Guided by the visible but skillful hand of their governments, these "tiger economies" seized the opportunity for rapid industrialization offered by trade with, and unimpeded flow of capital investment from, the leading capitalist countries. Strategic considerations in the context of the Cold War helped to make the West a willing partner in these exchanges. But relative demographic size clearly facilitated that willingness. Even if Japan is included among the newly industrializing trading partners - and, of course, by the 1970s Japan was solidly positioned within the core of the capitalist world-their combined population, or, more relevantly, the combined size of their potential labor resources, represented a small fraction of the labor force of the leading capitalist countries. Any pain from losing industrial jobs to the East Asian tigers was clearly overshadowed by the economic gains generated by increased trade.

Not surprisingly, the lessons of success are eventually absorbed by others, and the recipes are adopted. The big turnaround came in China, marked by the Dengist reforms of the early 1980s that freed trade between China and the outside world and opened the Chinese market to foreign investment. The ranks of imitators thereafter grew rapidly. The latest major convert to the advantages of exploiting the global marketplace has been the formerly autarky-seeking, reform-socialist India. Today, despite the loud protests voiced at successive World Social Forums, ostensibly speaking on behalf of the world's poor, there are hardly any less developed countries that wish to shut themselves off from globalization.

For the industrialized countries, however, this new globalization of globalization presents an unprecedented challenge. It places them in competition with newly emerging industrial countries that possess labor forces, actual and potential, vastly greater in size than their own and does so under circumstances in which the former advantages that favored them in such competition are rapidly disappearing. The problem is highlighted in warnings insistently issued to the citizenry in the EU and, with less justification, in the United States: "You must work harder and longer than before; you must give up privileges to which you have grown accustomed; and even if you do so, your job may evaporate tomorrow." Why? "Because of globalization! You are in competition with countless millions of workers in faraway lands who are eager and able to do what you do and do it just as well, and are willing to do it for wages that are a fraction of yours."

Such rhetoric in part simply draws attention away from problems that have nothing to do with globalization but derive from features in the existing design of systems of social protection that are becoming unsustainable because of population aging. These problems require domestic reforms, regardless of the extent of exposure to foreign competition. But the element of truth the warnings contain, when considered alongside the demographic realities alluded to, warrants further examination. What is at issue is the viability of the WTO trade regime from the standpoint of the developed world over the lengthy periodperhaps decades-during which technological differences between the demographic giants largely vanish but substantial wage differentials persist. 


\section{Offshoring and the demographic overhang}

In the past, the relatively high wages (and high non-wage costs) prevailing in the rich countries were routinely explained and justified by the higher productivity of their workers. That competitive edge derived from advantages that developing countries were once unable to replicate - a well-educated labor force that has privileged access to the best technology and to superior complementary factors of production such as management and marketing skills, organizational prowess, modern communication and transportation infrastructure, and a secure and healthy environment.

These advantages have fast been eroding as transnational corporations increasingly recreate them in locations where labor costs are much lower. Transferring industrial production to other countries then becomes an option favored by an elementary economic calculus. The wage differentials are initially seen in the "rubber shoes, bicycles, and umbrellas"-type manufactures. In the West, many one-time worriers about Japan's postwar economic predicament thought such products would be Japan's future way of earning a (modest) living through exports. Today no observer could miss the ability of China or India to produce a vast range of consumer and capital goods using the most advanced technologies, and their ability to sell such goods more cheaply than those manufactured in the high-wage industrial countries. China's Minister of Commerce, Bo Xilai, sought to defuse European objections to high levels of textile imports by remarking that China would need to sell 800 million shirts to afford one Airbus A380 (China Daily, 5 May 2005). A more significant calculation he did not essay was how long it would be before there was a Chinese-built A380.

Services are similarly prone to "offshoring" from high-income countries, and, as with manufacturing, skills in themselves offer no necessary protection. The criterion, as Blinder (2006) has noted, is whether the output of a job can be delivered electronically: "Janitors and crane operators are probably immune to foreign competition; accountants and computer programmers are not." Many jobs in the personal care industry - a growth sector in any country with an aging population — cannot be exported. And at least for a while, headquarters of transnational enterprises may remain in the centers from which much of the capital and most of the technology driving the new industrialization still originate. In this last case, however, even if such geographic specialization could be seen as permanent, favoring a well-compensated elite, not everybody in the former seats of manufacturing can be a banker, a lawyer, an advertising and public relations executive, marketing strategist, systems analyst, or management consultant. Moreover, research and development activities - the laboratories that power innovation and raise productivity-are among the strongest current candidates for outsourcing to China and India. The "symbolic analysts" who were to maintain the technical edge of the West's postindustrial economies are then as likely to be found in Shanghai and Bangalore as in Silicon Valley or the two Cambridges.

A more promising and steady jobs-assuring and export-earning large industry in the advanced stage of international specialization could be tourism-say, between the EU and the emerging modern Asia. In essence, Europe could be transformed into a huge theme park, geared for the entertainment of curious visitors, increasingly comprising the newly rich of Asia. In the ensuing equilibrium position, general material affluence might reign. 
But such a future, even on aesthetic grounds, would not appeal to countries with the memory of a quite different history.

Enthusiasts for globalization, whether seeing it as accelerating world development or as improving returns to capital, do of course recognize the major adjustment problems that offshoring imposes on developed-country workforces-even after taking account of the lower prices of the foreign-sourced goods and services and, partly in consequence, lower inflation. But they argue that any disadvantage is temporary: currencies will adjust to correct some of the trade imbalance, and industrial wages will quickly rise in the new locations. The problem with this expectation lies in the sheer demographic scale of the emerging economies. China and India, and many countries coming behind them, have large labor reserves in the traditional sectors of their economies that will not be exhausted for decades to come and will keep wages down. (That expectation is not belied by signs of upward pressure on wages, as observed recently in urban China. More probable explanations would point to temporary labor market frictions and educational bottlenecks.) For the West, moreover, a shift in manufacturing locations from China or India to Vietnam or Bangladesh would be no gain: the bottom line is the still-massive rural and fringe-urban populations in emerging manufacturing economies, providing several decades of something approaching an "unlimited" labor supply. As long as these populations exist and can be mobilized, permitting wage equalization upward would retard full modernization of the countries that possess them.

The absolute numbers of potential entrants to the modern economy are sobering. UN projections of urban growth extend only to the next 25 years, but they show proportions rural in 2030 still at 40 percent in China and nearly 60 percent in India (Table 5). In China, admittedly, that population will by then be aging rapidly; but elsewhere, notably in India, the cohort of entrants to the labor force shows only modest fall-off-even, as seen in Table 6 , under the UN's most optimistic scenario of fertility decline. (Table 6 also indicates the mounting uncertainties in these forecasts beyond 20 to 30 years, reflecting different but still quite feasible assumptions about trends in fertility.) The overall demographic contrast over time with the United States and the European Union, the two main components of the West, is seen in Figure 2.

This line of argument is set out in only the sketchiest terms, and may seem overdrawn. But its consideration in the ongoing debate about the merits of globalization is likely to be unavoidable. The weight of academic opinion, especially among economists (for example, see Lal 2006), is on the side of pushing ahead along the track we are on. But popular opinion disagrees, and its potential for exploitation by populist demagogues is all too real. ${ }^{14}$

Are there alternative models for the organization of the international system over the next few decades that might lessen the opportunity for and appeal of demagoguery? One that is worth fuller consideration (it is discounted by Lal) might be described as "regional quasi-autarky." What this entails is not a return to inward-looking protectionism at the country level: that has no attraction-if indeed it were even feasible. But a regional grouping of countries of comparable income levels, together offering a substantial productive base and internal market, could make good sense. A European Union is large enough, with 
nearly half a billion people, to exploit almost all conceivable economies of scale (perhaps only the Airbus actually requires a global market) and to provide a competitive environment assuring innovation and steadily improving product quality. Within its boundaries its rules already forbid protectionism. And it is large enough to provide balance-a diversity of industries and activities allowing for complementarities and unplanned synergies. How much more advantage can be squeezed out of extra diversity, in a region where Finns rub shoulders with Portuguese and Irish with Greeks? In short, as a region in itself the EU could flourish with a fair degree of autarky (energy excepted), working primarily to satisfy its internal market. The same recipe could fit North America or a larger Western Hemisphere grouping. And something similar could be fashioned from what some already call China's co-prosperity sphere, or an analogous region for India. These regions (say, those identified in Table 4) could live in peace with each other-a supposed attribute of democracies-and also trade. The EU needs some exotic spices; its citizens want to visit the Great Wall, the Grand Canyon, and the Taj Mahal. Mutatis mutandis, each of the other regions has comparable needs and desires. As with the EU and the United States today, there would be no objection to crafting special trade relationships in support of particularly backward economies.

In a more remote future, setting aside all that may go wrong, population pyramids around the world will even out—and, we can hope, will not have converged to the inverted pear-shaped structure. Worldwide economic prosperity of a sort will have been attained. In such a world, true globalization is likely to emerge as a real option. That future, however, not least for solid demographic reasons, is not within our grasp in the next 50 years.

\section{An Underclass of States?}

The "global" in globalization and the global economy thus far and perhaps well into the future is less than all-encompassing. A significant number of countries have fairly negligible links with the major trading economies aside from the trickle of imports financed by foreign aid; others have substantial exports but deriving from extractive-industry enclaves with revenues diverted to a narrow elite in the society. For whatever reason-there are many candidates - these countries have not managed to find or hold to the development path taken by the successful emerging economies. Disproportionately they are located in sub-Saharan Africa.

Per capita GDP in sub-Saharan Africa, based on Maddison's (2003) calculations, has hardly moved since the 1970s. The two vaunted regional high-flyers, Botswana and Mauritius, are impressive exceptions but their combined populations amount to less than 0.5 percent of the regional total. The past ten years have seen an improvement in this dismal record, which some observers believe may presage a larger turnaround under which Africa would slowly regain the economic promise that it possessed in the immediate aftermath of decolonization in the 1960s. That, at least, is the vision promulgated by the Commission for Africa, whose 2005 report was endorsed by the G-8 and by major foreign-aid donor agencies. It is implicit in the rhetoric of the African Union and its NEPAD (New Partnership for Africa's Development) initiative. The factors militating against such a turnaround, though, are formidable. 
The AIDS epidemic is one such factor. The bleak future for sub-Saharan Africa portrayed by Christopher Clapham (2006) has much to do with AIDS. The extraordinary fall in life expectancy at birth beginning in the 1990s in South Africa, Botswana, and Zimbabweby 20 years or more, to numbers not seen at a country level for many decades-presents huge development problems in addition to the tragedy it represents for individuals, families, and communities. Predictions of the future course of the AIDS epidemic vary widelyindeed, even estimates of current HIV prevalence rates are often questioned — but many analysts have retreated from earlier dire predictions of a continent-wide pandemic. Some countries that had experienced high rates of HIV prevalence and AIDS mortality in the early years of the epidemic have managed to reduce both; others, against expectations, seem to have largely avoided epidemic rates of infection. These outcomes apparently stem from some combination of health education, modifications in sexual behavior, interventions to prevent mother-to-child HIV transmission, and the fortuity of particular cultural practices (such as male circumcision, which apparently lowers infection risk). It is not wholly implausible that even without wide access to effective medical treatment—still a distant prospect for much of the region - the impact of the disease will gradually subside to a level that, while still serious, is more comparable to that of other health risks.

Heavy AIDS mortality over coming years but a less-than-dire scenario for the duration and spread of the epidemic are the assumptions made in the current UN population projections for Africa. As Table 2 showed, the medium projections for 2050 foresee a Uganda of 127 million, an Ethiopia of 170 million, a Congo of 177 million, and a Nigeria of 258 million. Overall, sub-Saharan Africa is expected to grow from 0.75 billion in 2005 to 1.69 billion in 2050; at midcentury, even though average fertility is assumed to have halved from its current level, the absolute annual increase in population would still be growing. This added weight of numbers will be a burden on development efforts and intensify already severe problems of governability. Glib assertions about economy-boosting demographic bonuses provided by favorable youth-dependency ratios - the potential reallocations from consumption and capital-widening expenditures to growth-enhancing investments-presuppose just those conditions of social order and administrative capacity that rapid population growth threatens.

A sanguine prognosis for the region would see some countries doing well (South Africa is the main hope among the larger economies) and many others, in one way or another, advancing at a pace sufficient to allow substantial improvement in social and economic conditions. Even under such a favorable outcome it is all but certain there will also be laggards and backsliders. States that combine poverty, economic retrogression, and pervasive domestic insecurity can be described as failing or, where these conditions have been longstanding, as "failed." African examples include Angola, Burundi, DR Congo, Guinea, Ivory Coast, Liberia, Sierra Leone, Sudan, and Zimbabwe. The category is far from clearcut and by no means precludes a state so described eventually regaining a foothold on the development path—-though it may be starting from a much lower position. ${ }^{15}$

Failing or failed states are not found only in Africa. Afghanistan, East Timor, Haiti, Iraq, Nepal, North Korea, Papua New Guinea, and Yemen are among others that also fit the description. Few are populous: only in sub-Saharan Africa and perhaps the south-western 
Pacific do such states amount to a significant fraction of their respective regional populations. By some assessments, however, states "at risk" include Nigeria, Bangladesh, and Pakistan. That would lend the problem a truly ominous global dimension. ${ }^{16}$

But even a lack of significance in economic and demographic terms does not mean that failed states have no bearing on the evolution of the global economy and polity. The energy exporters among them obviously remain important in a tight suppliers' market for fossil fuels. Others figure disproportionately as sources of refugees and, through criminal and terrorist activity, as regional destabilizers or even threats to more distant states. And without functioning civil administrations, they are ill-equipped to combat infectious disease or environmental destruction, both with potential for damaging spillover effects beyond their borders.

\section{UNCERTAINTIES AND SURPRISES}

The varying assumptions underlying population forecasts like those of the United Nations concern the pace of fertility transition, ${ }^{17}$ which in turn reflects the course of economic growth and cultural change. As was discussed above and in Chapter 1, such forecasts can go seriously awry over a span of half a century even without effects that would count as surprises. Interestingly, however, most of the dramatic events that are thereby ignoredwars, famines, floods, plagues - are barely visible at the broad regional scale and not at all at the global level. Thus the 1959-61 Great Leap Forward famine in China, perhaps the largest in history, killing some 30 million, can hardly be discerned in an East Asian population series. AIDS deaths in the tens of millions in sub-Saharan Africa go with a projected net addition of one billion persons in that region (150 percent) over the half-century to $2050 .{ }^{18}$

In his assessment of the risks of other such "fatal discontinuities" in this period, from asteroid collisions to microbes and nanobots, the geographer (and polymath) Vaclav Smil (2005a) finds most of the usual candidates for worldwide catastrophe comfortably distant or improbable. ${ }^{19}$ Influenza and war are the main exceptions-with broadly similar riskfatality profiles. A worldwide influenza epidemic is seen as unavoidable in the next few decades - the unknown being whether its fatalities can be kept down to a few tens of millions. ${ }^{20}$ Precisely because its effects would be so widespread, however, a flu pandemic is not likely to be a destabilizing force in the global political economy. That is not true for war, which ample historical precedent shows can be genuinely transformational. While encouragement can be taken from the declining trend in major conflicts over the twentieth century, ${ }^{21}$ what in the past have turned out to be transformational wars have sometimes been wholly unforeseen.

Discontinuities in the evolution of the global system can come about without mass fatalities. Environmental change offers several such scenarios, and doubtless many others that have not been imagined. The gradual atmospheric warming over the twenty-first century, predicted by general circulation models of the climate system, is the best known of these scenarios-its most severe effects coming later in the century but likely to be clearly visible well before. There are potentially large implications for the regional distribution of 
agricultural zones, for the prevalence ranges of particular infectious and parasitic diseases, and for coastal erosion and flooding from a rise in sea levels, in addition to drastic effects on the nonhuman biota. Rising fossil-fuel use and resultant greenhouse gas emissions, the main anthropogenic factor in global warming, owe more to economic than demographic expansion. But per capita emissions, bound to rise fast in China, India, and the other main emerging economies even under optimistic assumptions about abatement technologies, are multiplied by these countries' huge population numbers.

Wealth brings improved means to adapt to change, so global inequalities will be accentuated by these environmental effects. Many poor countries are particularly vulnerable. New food-deficit regions will probably emerge-and new areas of surplus-calling for major adjustments in the international trade in cereals. Coastal settlement will be affected: in more alarmist scenarios, "environmental refugees" would be created in great numbers.

Responsibility for damage, once assigned, elicits demand for compensation. In the international arena such claims are sometimes recognized-for wartime occupation, for instance-typically through ad hoc bilateral negotiations. The possibilities of broad-scale damage to particular groups of countries through climate change may elicit claims of an altogether greater magnitude. The guilty parties - guilty of a kind of aggression, from one perspective-would be the industrialized countries, many of them not only current large emitters but the main contributors to the build-up of greenhouse gases over decades past. Adjudication of such claims may well devolve into more rounds of debate like those that have taken place in follow-up meetings on the 1992 Climate Convention (one of which produced the Kyoto Protocol), yielding treaties notably lacking in enforceable sanctions for nonperformance and with few repercussions on other spheres of international relations. Or, it may be that these distributional issues originating in environmental change will become a dominant concern for the international system.

Climate modeling of the kind that underpins the projections of the Intergovernmental Panel on Climate Change yields smooth output trajectories - a warming, say, of a few degrees Centigrade by the end of this century. But sudden climatic shifts, beyond the predictive ability of current models, also seem possible. A widely publicized scenario of this sort is for ocean warming to disrupt heat circulation by ocean currents in the North Atlantic, and in particular to halt the moderating effect of the Gulf Stream on the climate of Western Europe. (Edinburgh and Copenhagen are on the same latitude as Moscow.) Research on the fine detail of climate history has uncovered many instances in the distant past of abrupt regime change-major (say, $10^{\circ} \mathrm{C}$ ) rises or falls in mean temperatures in a region, sometimes taking place in a period as short as a decade but lasting perhaps for centuries. ${ }^{22}$ What can set off such events is unknown, but their existence adds to the range of uncertainty surrounding the effects of present trends in atmospheric composition.

Climate change aside, environmentalists also point to looming problems of degradation of ecological services - the often unpriced benefits humans receive from the various ecological systems they are part of. Examples of ecosystem services are crop pollination, fresh water supply from streams and aquifers, natural processes of soil formation and erosion control, nutrient cycling, and photosynthesis. Mounting evidence indicates that many 
such services are being degraded or drawn on at unsustainable rates, as a consequence of population growth, economic expansion, and poor management practices. ${ }^{23}$ Here too there are many possibilities for repercussions for human well-being and for economic and political systems beyond national borders.

A particular class of ecosystem service has to do with the aesthetic values humans derive from the natural environment. Those amenity values can in some measure be pricerationed like ordinary goods and services, thereby limiting adverse congestion effects for users. Population growth itself has been a factor in the enclosure or privatization of many common-access resources. But given the choice, most people would likely resist that privatization route beyond modest limits, preferring to retain open access. Unless other kinds of rationing can be devised, degradation through overuse becomes a serious risk. David Victor (2006) addresses these issues in relation to wilderness areas. The international spillovers implicated in wilderness preservation or wilderness destruction are mostly intangible - the satisfaction many people find in knowing of their existence, and the pain over their loss-but not a negligible element of welfare. Some conservation efforts attempt to translate those sentiments into monetary terms.

\section{FUTURES FOR THE DEMOGRAPHIC FORERUNNERS}

In the very long term, beyond the time-horizon of this essay, full or near-full global convergence in demographic patterns might be achieved, along with—most would no doubt hope-a fairly stationary population or one trending slowly downward to a preferred global optimum. That is the future that the cosmologist Fred Hoyle (1963), in a brief foray into demography, called dull (his less-dull alternative was a time-series of population explosions and collapses), although a vision of human continuity is hard to reconcile with large departures from demographic stationarity. Dullness is not a risk over the next 50 years. ${ }^{24}$

The coming half-century is likely to see the ending of massive global population expansion - at least, if the UN medium-variant projections are borne out. ${ }^{25}$ The demographic marginalization of the countries currently classified as "more developed" vis-à-vis those classified as "less developed" will proceed apace, with a ratio of 1:10 in births virtually unchanged over the period. The striking contrasts in age structures across countries and regions will also persist, although lessening by midcentury. ${ }^{26}$ These differentials and trends have ramifying effects on the international political economy. For the more developed countries, they pose dilemmas for public policy, the chosen resolution of which will have profound implications for the societies and cultures that emerge.

Low fertility was discussed above as one of the main threats to the European social model, as it is to Japan's also. Continuation of the ultra-low fertility now experienced in Japan, Russia, and parts of the EU leads to a rapid and hard-to-reverse downward trend in population. Under the UN low-variant assumptions, for instance, Japan's and Italy's populations would both diminish by nearly one-quarter by 2050 , Russia's by more than one-third. Future levels of fertility stuck below 1.5 children per woman are quite plausible — even as a Europe-wide average - implying, if maintained, generational population declines (aside from migration) of more than 25 percent. Accompanying those declines would be burgeoning pro- 
portions of the old and very old, requiring costly medical care (and invidious rationing) ${ }^{27}$ As a long-run prognosis offered as an option in a policy debate, this demographic outlook might well be judged unacceptable. Its presence in the background sets the stage for consideration of expanded immigration on the one hand and pronatalist measures on the other.

Mere numbers, of course, are only the simplest of the issues that migration policy needs to be concerned with, but they are a convenient starting point. Low or moderate rates of immigration, combined with expectations of (and supporting measures for) integration, are unexceptionable responses to below-replacement fertility. Migration at rates that would be needed to significantly offset very low fertility, however, is a different matter. Integration then becomes far more problematic, and there is a likelihood of generating or further exacerbating serious cultural tensions. Even moderate inflows can yield high urban or fringeurban concentrations of immigrants, impeding assimilation - and, in the subsequent generation, producing alienation and anomie among persons with cultural roots in neither their parents' society nor the one surrounding them.

Heavy reliance on migration, as earlier remarked, is in some sense an easy option for public policy, assuming that ethnic and cultural tensions can be kept in check. But in avoiding the institutional reforms that would be called for in adapting to a low-fertility, aging society, political leaders and their constituents are setting the stage for a deeper societal transformation. Historically, of course, that has happened often enough, but it entails a potentially huge loss of cultural patrimony. Such a calculation may no longer have much force in affluent, late-capitalist societies - with individualism triumphant and self-fulfillment acknowledged by many as a principal goal. But realization of impending transformation can also be a potent generator of populist reaction.

Maintaining fertility at a level that does not fall much below a two-child average - say, around 1.7-1.8-would largely avert this problem. Such levels (arguably creditable to some extent to supportive population policies) are found in some countries of Western and Northern Europe and in Australia and New Zealand; in the United States, fertility is even higher. But for those many countries in Europe - and for Japan-where levels are well below 1.5, that prospect is dim. ${ }^{28}$ There are narrow limits to welfare-state generosity in bribing wouldbe parents, especially when the state is already overburdened with pension and health-care costs. There is a reluctance to make family allowances disproportionately high for third or later children-or for higher-income parents. There is lingering ideological resistance to the state trying to override personal preferences about childbearing. There is a strong economic interest in increasing female labor force participation, which, policy efforts notwithstanding, is a discouragement to childbearing. ${ }^{29}$ And the state is powerless to counter cultural and value changes that favor low fertility or even childlessness. It is possible to imagine a spontaneous recovery in birth rates, like the prosperity-linked baby boom in the years after World War II or, more speculatively, through some radical cultural shift — a millenarian movement? - as yet unforeseen. The role for social policy in engineering an upturn, however, seems fairly marginal. ${ }^{30}$ Even if an upturn were to happen, moreover, it would take a quarter-century before the new homegrown labor force began to be felt in the economy; the migration alternative is at hand and has no delay. 
As this discussion makes clear, the post-transition demographic predicament of the low-fertility West - the European Union and Japan most notably - is both serious and intractable. That appreciation should argue for concentrated deliberation over what kinds of societies and economies these countries should be trying to construct for themselves and about how they might protect them through the remaining decades of the global demographic transition. Over most of that time they must expect to be continually challenged by low-wage but high-skilled competitors in the world's populous dynamic economies over the whole range of tradable goods and services; at the same time, they will face continued clamoring for entry to their societies by a stream of would-be economic migrants and refugees from fragile or failing economies. Against these formidable pressures they must seek to maintain the levels of social protection and leisure and the other components of the quality of life that affluence has won for them, in the face of further population aging and steadily diminishing numbers of native-born labor force entrants. If nothing more, the deliberation called for might begin a process of strategic thinking about these issues, helping to avert a day-by-day caving in of policy to narrowly based interests and recourse to leasteffort political remedies. In the long run, if environmental and other dangers can be held in check, most human societies will have to find their way through the same demographic landscape, hence the experience of the forerunners should have much to teach.

In the United States, fertility has remained close to a two-child average, well above European and Japanese levels, and immigrants—even unskilled immigrants, provided they carry the requisite documents - are broadly welcomed. (The main caveat on migration applies to the large inflow from Mexico, seen by some as the making of a culturaleven political-reconquista.) Hence, there is no prospect of population growth ceasing in the foreseeable future. Medium Census Bureau projections show the 2050 US population at 420 million, almost 50 percent above the 2000 census count; decadal increases are undiminished, in the range of 25-30 million. ${ }^{31}$ The words of the 1972 Commission on Population and the American Future ("recognizing that our population cannot grow indefinitely," and recommending "that the nation welcome and plan for a stabilized population"- the population was then 210 million) have been decisively sidelined if not altogether rejected.

In its absence of a sense of national population scale or interest in stabilization, the United States is something of an oddity in the developed world..$^{32}$ What might eventually change that situation is unclear: localized congestion does not seem to. The contrast with other rich societies may extend to views of economic growth as well-albeit with elements of caricature on both sides. The vision Keynes spelled out in 1930, echoing John Stuart Mill a century earlier, plausibly resonates more in Europe and Japan than in the United States. The struggle for material goods, said Keynes (1963: 365-366), should not be "the permanent problem of the human race." He looked for a time when both material and demographic growth will have ceased, with attention turned to intellectual and aesthetic endeavors.

$[F]$ or the first time since his creation man will be faced with his real, his permanent problem-how to use his freedom from pressing economic cares, how to occupy the 
leisure, which science and compound interest will have won for him, to live wisely and agreeably and well.

A contrasting vision of the pursuit of happiness is that described by Richard Easterlin (1996: 153-154)—a perspective with a distinctly American flavor:

The future, then, to which the epoch of modern economic growth is leading is one of never ending economic growth, a world in which ever growing abundance is matched by ever rising aspirations, a world in which cultural differences are leveled in the constant race to achieve the good life of material plenty.

The world in which either of these futures might be near to realization will also contain plenty of economic laggards. Some will be on an upward path—eased, no doubt, by flows of investment funds from the developed world, seeking economic returns wherever they can be found. But others might be more in the position of wards of the international community - though exposed to an ever-present risk of default on the part of that community and with their prospects worsened to the degree that any exceptional human talent they produce is siphoned off. Foreign assistance will still have a role, both in covering troughs in food production and in promoting development and demographic transition. Whether it can do so without repeating the many fruitless efforts of the past-by drawing on mature reflection on what should have been done in the last half-century_-is far from certain.

\section{NOTES}

1 As the earlier comments indicate, those labels are already highly tenuous. Convenience and convention are their only defense.

2 The term "Muslim tier" is used in Demeny (2003), where it refers to an arc of 25 predominantly Muslim countries from Pakistan to Mauritania (excluding former Soviet republics); here it is defined so as to exclude five of those 25 countries that the UN places in sub-Saharan Africa.

3 Goldman Sachs forecasts from Wilson and Purushothaman (2003); purchasing power parity estimates for 2001 from Maddison (2003).

4 Typically, the dependency ratio is defined as the population below age 15 and aged 65 and above divided by the population aged 15-64. This age range is of course arbitrary and, especially in advanced economies, at best a crude reflection of reality.

5 Individual accounts, however, offer no more protection than pay-as-you-go schemes against the risk of falling market value of accumulated capital caused by the shifting proportions of workers to retirees. On this "asset meltdown" prospect linked to population aging, see Poterba (2005). 
6 Future latecomers to population aging, and economically disadvantaged countries in general, do not have recourse to such a solution. Its present-day use, therefore, has some characteristics of a Ponzi scheme.

7 The contrast is even sharper if the comparison looks only at workforce ages—say, the age group 20-59. In 2005 the 20-59 population in each of the two groups is about 110 million. Over 2005-2050, the EU group drops to 89 million, the southern neighbors increase to 172 million.

8 See Annan (2004). It is now often argued that the logic of globalization should lead not only to free movement of goods and capital but also to free movement of labor. For example, the report of the ILO-sponsored World Commission on the Social Dimension of Globalization (2004) called for "a multilateral framework for immigration laws and consular practices...that would govern cross-border movement of people," paralleling similar frameworks for "cross-border movement of goods, services, technology, investment and information."

9 At least for professionals. (Malaysia periodically expels undocumented Indonesian workers.)

10 Boniface (1998) argues on those lines, seeing the rush toward secessionism as driven by efforts of the territorially clustered rich to shed obligations toward the adjacent territorially clustered poor.

11 The impending entry of Bulgaria and Romania and, almost certainly, Croatia would add some 34 million to form an EU-28.

12 See MacIntyre and Naughton (2005). A recent conference report from the US National Intelligence Council (2004) foresees "China's benevolent dominance" of the region in economic and security affairs as likely to be in place by 2020 .

13 World Bank (2005); Wilson and Purushothaman (2003: 9). Maddison's estimates for 2001 show Brazil's economy already one-third larger than Mexico's (Maddison 2003: 134).

14 A link between the demography of globalization and reactionary populism-but referring to immigrant European labor in the United States rather than to production outsourcing, and to the late nineteenth and early twentieth century rather than to the present era of globalization-is discussed by James (2001).

15 A summary of a recent conference of "top US experts on Sub-Saharan Africa" gives a more somber appraisal: "there is a class of African countries-which includes Burkina Faso, Central African Republic, Chad, Mali, Mauritania, and Niger-that are so burdened by their extreme climate, related problems of health and disease, and poor geographic position that it is not clear that any economic model offers them a path toward development" (US National Intelligence Council 2005). 
16 A "failed state index" published annually by the magazine Foreign Policy lists no fewer than 60 countries "at risk," containing one-third of the world's population.

17 The assumptions concerning future trends in mortality and international migration are the same for each of the variants.

18 The low-variant projection shows a 118 percent increase over 2000-2050; the high variant, 189 percent.

19 Smil (2005a: 229) summarizes his findings and informed speculations on the risk and effect of "massively fatal discontinuities" in a simple graph plotting number of fatalities against probability of occurrence over the next 50 years on a double log scale. At 10 percent probability - a risk that many would regard as considerable reason for worry over that time interval — the three globally significant calamities are an influenza pandemic of a scale to cause around 50 million deaths, war (around 20 million deaths), and volcanic eruptions or tsunamis (1 million deaths). At 100 percent, the fatality expectations for the three events are about 25 million, 4 million, and 150,000 respectively. Asteroid collisions, the reader is pleased to discover, are not something to lose sleep over, with a 10 percent risk of about 50 fatalities. (An impact causing one million fatalities is put at .01 percent probability for the period.)

20 Other as yet unknown viruses with epidemic potential may well be in the wings, able in the right circumstances to cross to humans from animal hosts (see Lederberg 1988).

21 See the data and time-series compiled in Human Security Centre (2005).

22 See National Research Council (2002).

23 Bleak depictions are set out in great detail in the authoritative Millennium Ecosystem Assessment reports. See «www. millenniumassessment.org».

24 Smil (2005b: 636) concludes his two-part essay on the subject as follows: "[I]f you take a long look back and then try to discern what may come, if you ponder the reiteration of catastrophe throughout history and think about human irrationality, hatred, and drive for power and dominance, and about the fate of aerosols, bees, and bacteria, then you might conclude that, despite so many atrocities, failures, and fears, the past 50 years were an exceptionally stable and an unusually benign period in human history and that the probabilities of less benign events will greatly increase during the next 50 years."

25 The medium-variant of the UN long-range projections published in 2004 shows world population edging up from 8.9 billion to 9.1 billion in the half-century after 2050 and subsequently dropping back. (The low-high ranges, however, are large: 7.4-10.6 billion in 2050; 5.5-14.0 billion in 2100.) See United Nations (2004, 2005).

26 While in both regions the absolute number of the elderly will expand dramatically, the proportions will still be far greater in the more developed countries. The 80+ 
population in 2050 is projected to amount to 15 percent and 12 percent in Japan and Germany, 7 percent and 3 percent in China and India. The corresponding absolute numbers in this age group will be 17 and 10 million in Japan and Germany, 101 and 53 million in China and India. (United Nations 2005.)

27 Future technological breakthroughs, anticipated by some experts, may extend the human lifespan well beyond the business-as-usual extrapolations assumed by the United Nations. Within countries this could heighten the tensions inherent in allocative decisions on publicly financed health care (access could hardly be denied to those willing to pay). It also has the potential to generate analogous international dissatisfactions, or at least to amplify envy.

28 To an appreciable extent, very low levels of total fertility (TFR) defined at a given time are a consequence of women delaying their childbearing to later ages, rather than cutting back on their completed family size. That delay option has an evident biological upper limit which, as it is approached, may lead to some recovery in TFR. How significant such a recovery might be in practice is not known.

29 The main pronatalist policy mantra-make female labor force participation compatible with childbearing - has obvious limits: it virtually rules out families with three or more children, but not childlessness.

30 An avenue for social policy that for the most part has yet to be explored will be concerned with anticipated developments permitting genetic engineering in utero or in vitro. Parents would likely demand a major role in what, in effect, would be grassroots eugenics, but there is an equally evident public interest in the matter-albeit well short of Brave New World scenarios. International differences in the ethical premises and design of such social policy (the requisite know-how would rapidly spread among the technologically adept) may be substantial.

31 US Census Bureau (2005).

32 The reasons probably have to do with the concentration of immigrants in a few states and the design of congressional representation in the two houses. (Scale is also a matter to which economists pay little attention.)

\section{REFERENCES}

African Union Commission. 2004. Strategic Plan of the African Union Commission. Addis Ababa.

Annan, Kofi A. 2004. "Why Europe needs an immigration strategy" «http://www.un.org/ News/ossg/sg/stories/sg-29jan2004.htm».

Blinder, Alan S. 2006. “Offshoring: The next industrial revolution?” Foreign Affairs 85(2): $113-128$. 
Boniface, Pascal. 1998. “The proliferation of states," The Washington Quarterly 21(3): 111127.

Buzan, Barry. 1998. "System versus units in theorizing about the Third World." In S. G. Neuman (ed.), International Relations Theory and the Third World. New York: St. Martin's Press.

Clapham, Christopher. 2006. "The political economy of African population change," in Paul Demeny and Geoffrey McNicoll (eds.), The Political Economy of Global Population Change, 1950-2050, supplement to Population and Development Review 32: 96-114.

Commission for Africa. 2005. Our Common Interest: Report for the Commission for Africa. [London].

Cooper, Robert. 2003. The Breaking of Nations: Order and Chaos in the Twenty-first Century. New York: Atlantic Monthly Press.

Demeny, Paul. 2003. "Population policy dilemmas in Europe at the dawn of the twenty-first century," Population and Development Review 29: 1-28.

Easterlin, Richard A. 1996. Growth Triumphant: The Twenty-first Century in Historical Perspective. Ann Arbor: University of Michigan Press.

Hoyle, Fred. 1963. A Contradiction in the Argument of Malthus. Hull, UK: University of Hull Publications. (Reprinted in Population and Development Review $12(3), 1986$.

Human Security Centre. 2005. Human Security Report 2005: War and Peace in the 21st Century. New York: Oxford University Press.

James, Harold. 2001. The End of Globalization: Lessons from the Great Depression. Cambridge, MA: Harvard University Press.

Keynes, J. M. 1963 [1930]. "Economic possibilities for our grandchildren," in his Essays in Persuasion. New York: W.W. Norton, pp. 358-373.

Lal, Deepak. 2006. "India: Population change and its consequences," in Paul Demeny and Geoffrey McNicoll (eds.), The Political Economy of Global Population Change, 19502050, supplement to Population and Development Review 32: 145-182.

Lederberg, Joshua. 1988. "Medical science, infectious disease, and the unity of mankind," Journal of the American Medical Association 260 (5): 684-685.

MacIntyre, Andrew and Barry Naughton. 2005. "The decline of a Japan-led model of the East Asian economy.” In T. J. Pempel (ed.), Remapping East Asia: The Construction of a Region. Ithaca: Cornell University Press.

Maddison, Angus. 2003. The World Economy: Historical Statistics. Paris: Organisation for Economic Co-operation and Development.

National Research Council. 2002. Abrupt Climate Change: Inevitable Surprises. Washington, DC: National Academy Press. 
Poterba, James M. 2005. "The impact of population aging on financial markets." In Gordon H. Sellon (ed.), Global Demographic Change: Economic Impacts and Policy Challenges. Kansas City, MO: Federal Reserve Bank of Kansas City.

Rosecrance, Richard. 1996. "The rise of the virtual state," Foreign Affairs 75(4): 45-61.

Smil, Vaclav. 2005a. "The next 50 years: Fatal discontinuities," Population and Development Review 31: 201-236.

- 2005b. "The next 50 years: Unfolding trends," Population and Development Review 31: 605-643.

Thomas, Albert. 1927. "International migration and its control," in Proceedings of the World Population Conference, Geneva, 1927. London: Edward Arnold.

United Nations. 2004. World Population to 2300. Department of Economic and Social Affairs. New York.

- 2005. World Population Prospects: The 2004 Revision. Volume I: Comprehensive Tables. Department of Economic and Social Affairs. New York.

— 2006. World Urbanization Prospects: The 2005 Revision-Population Database «http://esa.un.org/unup».

US Census Bureau. 2005. «http://www.census.gov/population/www/projections/ popproj.html».

US National Intelligence Council. 2004. "Conference report on Northeast and Southeast Asia.” (2020 Project Discussion Paper.)

— 2005. "Mapping sub-Saharan Africa's future: Conference report" «http://www.dni. gov/nic/confreports_africa_future.html».

Victor, David G. 2006. "Seeking sustainability: Cities, countryside, wilderness," in Paul Demeny and Geoffrey McNicoll (eds.), The Political Economy of Global Population Change, 1950-2050, supplement to Population and Development Review 32: 202221.

Wilson, Dominic and Roopa Purushothaman. 2003. "Dreaming with BRICs: The path to 2050,” Goldman Sachs Global Economics Paper, No. 99.

World Bank. 2005. World Development Indicators 2005. Washington, DC.

World Commission on the Social Dimension of Globalization. 2004. A Fair Globalization: Creating Opportunities for All. Geneva: International Labour Organization. 
TABLE 1 Population and population change by major country and region, estimates and projections, 1950-2050

\begin{tabular}{|c|c|c|c|c|c|}
\hline \multirow[b]{3}{*}{ Country/region } & \multirow{2}{*}{\multicolumn{3}{|c|}{ Population (millions) }} & \multicolumn{2}{|c|}{ Percent increase } \\
\hline & & & & \multirow{2}{*}{$\begin{array}{l}1950- \\
2000\end{array}$} & \multirow{2}{*}{$\begin{array}{l}2000 \\
2050\end{array}$} \\
\hline & 1950 & 2000 & 2050 & & \\
\hline North America & 172 & 315 & 438 & 83 & 39 \\
\hline $\begin{array}{l}\text { Latin America and } \\
\text { the Caribbean }\end{array}$ & 167 & 523 & 783 & 213 & 50 \\
\hline Europe $^{a}$ & 547 & 728 & 653 & 33 & -10 \\
\hline (EU-25) & $(350)$ & $(450)$ & $(450)$ & 29 & 0 \\
\hline Muslim tier ${ }^{\mathrm{b}}$ & 148 & 545 & 1,109 & 268 & 103 \\
\hline Sub-Saharan Africa & 180 & 670 & 1,692 & 272 & 152 \\
\hline Japan & 84 & 127 & 112 & 51 & -12 \\
\hline China $^{c}$ & 549 & 1,259 & 1,382 & 129 & 10 \\
\hline India & 358 & 1,021 & 1,593 & 185 & 56 \\
\hline Southeast Asia & 178 & 519 & 752 & 192 & 45 \\
\hline Other Asia ${ }^{\mathrm{b}}$ and Oceania & 128 & 379 & 562 & 196 & 48 \\
\hline World & 2,519 & 6,086 & 9,076 & 142 & 49 \\
\hline
\end{tabular}

ancluding Russia

${ }^{b}$ Muslim tier taken as 20 West Asian and North African countries (see endnote 2).

'Including Hong Kong, excluding Taiwan.

SOURCE: United Nations 2005 (medium-variant projections); Taiwan Statistical Yearbook.

TABLE 2 Countries with populations above 100 million, 2005 and 2050 (estimates and projections)

\begin{tabular}{lrlrr}
\hline 2005 & & & 2050 & \\
\cline { 5 - 5 } Country & Population & & Country & Population \\
\hline China & 1,300 & & India & 1,593 \\
India & 1,103 & & China & 1,382 \\
United States & 298 & & United States & 395 \\
Indonesia & 223 & & Pakistan & 305 \\
Brazil & 186 & & Indonesia & 285 \\
Pakistan & 158 & & Nigeria & 258 \\
Russia & 143 & & Brazil & 253 \\
Bangladesh & 142 & & Bangladesh & 243 \\
Nigeria & 132 & & Congo DR & 177 \\
Japan & 128 & & Ethiopia & 170 \\
Mexico & 107 & Mexico & 139 \\
& & Philippines & 127 \\
& & Uganda & 127 \\
& & Egypt & 126 \\
& & Viet Nam & 117 \\
& & Japan & 112 \\
& & Russia & 112 \\
& & Iran & 102 \\
& & Turkey & 101 \\
\hline
\end{tabular}

SOURCE: United Nations 2005 (medium-variant projections); China excluding Taiwan. 
TABLE 3 Projected proportions of population below age 15 and aged 65 and older, selected countries and regions, 2005, 2025, and 2050

\begin{tabular}{|c|c|c|c|c|c|c|}
\hline \multirow[b]{2}{*}{ Country/region } & \multicolumn{3}{|l|}{ 0-14 } & \multicolumn{3}{|l|}{$65+$} \\
\hline & 2005 & 2025 & 2050 & 2005 & 2025 & 2050 \\
\hline Japan & 14.0 & 12.5 & 13.4 & 19.7 & 29.1 & 35.9 \\
\hline EU-25 & 16.4 & 14.4 & 13.4 & 16.4 & 22.6 & 29.9 \\
\hline United States & 20.7 & 18.7 & 17.3 & 12.3 & 17.7 & 20.6 \\
\hline China & 21.4 & 17.9 & 15.7 & 7.6 & 13.7 & 23.6 \\
\hline India & 32.1 & 24.4 & 18.3 & 5.3 & 8.1 & 14.8 \\
\hline Africa & 41.5 & 36.9 & 28.7 & 3.4 & 4.2 & 6.7 \\
\hline
\end{tabular}

SOURCE: United Nations 2005 (medium-variant projections) and Eurostat.

TABLE 4 Population sizes of major regional trade pacts or common markets (existing or in prospect), 2005 and as projected to 2050 (millions)

\begin{tabular}{lcc}
\hline & $\mathbf{2 0 0 5}$ & $\mathbf{2 0 5 0}$ \\
\hline European Union (EU-25) & 460 & 450 \\
NAFTA & 438 & 577 \\
CSN $^{\mathrm{a}}$ & 375 & 527 \\
APT (ASEAN Plus Three) $^{\mathrm{b}}$ & 2,031 & 2,285 \\
(ASEAN) $_{\text {SAARC }}$ & $(555)$ & $(749)$ \\
African Union & 1,453 & 2,220 \\
\hline
\end{tabular}

${ }^{a}$ Comunidad Sudamericana de Naciones (South American Community of Nations)

${ }^{\mathrm{b}}$ Comprising the ten members of the Association of Southeast Asian Nations, China, Japan, and South

Korea

'South Asian Association for Regional Cooperation

SOURCE: United Nations 2005 (medium-variant projections) and Eurostat. 
TABLE 5 Rural population size and proportions rural in China and India, 2005 and 2030

\begin{tabular}{llllll}
\hline & China & & & India & \\
\cline { 2 - 3 } \cline { 5 - 6 } $\begin{array}{l}\text { Rural } \\
\text { population } \\
\text { (millions) }\end{array}$ & $\begin{array}{l}\text { Percent } \\
\text { rural }\end{array}$ & & $\begin{array}{l}\text { Rural } \\
\text { population } \\
\text { (millions) }\end{array}$ & $\begin{array}{l}\text { Percent } \\
\text { rural }\end{array}$ \\
\hline 2005 & 784 & 59.6 & & 786 & 71.3 \\
2030 & 574 & 39.7 & & 859 & 59.3 \\
\hline
\end{tabular}

SOURCE: United Nations 2006 .

TABLE 6 Youth cohort size, China and India: Age group 18-23 years, 2000-2050 (in millions, showing low- and high-variant projection range)

\begin{tabular}{lllllll}
\hline & $\mathbf{2 0 0 0}$ & $\mathbf{2 0 1 0}$ & $\mathbf{2 0 2 0}$ & $\mathbf{2 0 3 0}$ & $\mathbf{2 0 4 0}$ & $\mathbf{2 0 5 0}$ \\
\hline China & 116 & 137 & $108-110$ & $85-121$ & $74-131$ & $61-119$ \\
India & 111 & 134 & $139-140$ & $124-157$ & $104-165$ & $86-160$ \\
\hline
\end{tabular}

SOURCE: United Nations 2005. 
FIGURE 1 Demographic background to European immigration: European Union (EU-25) compared to its "southern hinterland," 1950-2050

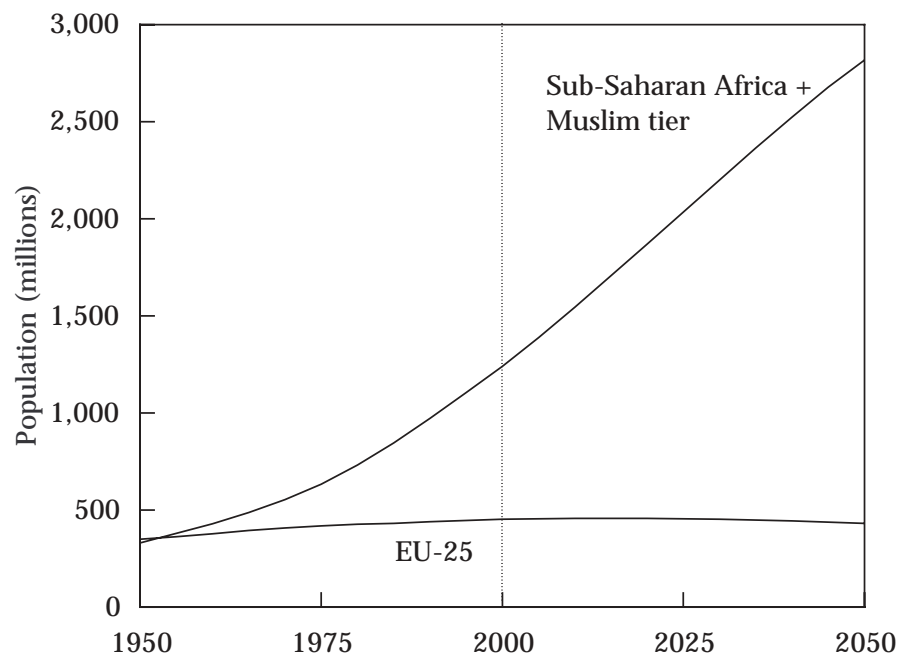

SOURCE: United Nations 2005 (estimates and medium-variant projections).

FIGURE 2 Demographic background to globalization: China and India compared to European Union (EU-25) and the United States, 1950-2050

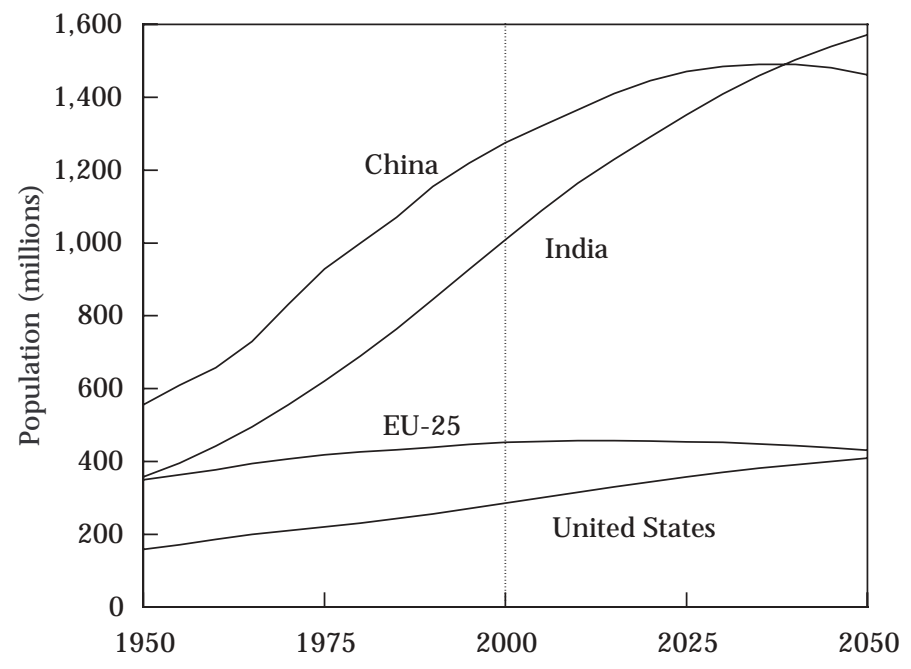

SOURCE: United Nations 2005 (estimates and medium-variant projections). 


\section{POLICY RESEARCH DIVISION WORKING PAPERS}

If still in print, single copies of up to three working papers from 1989 through 2003 are available free of charge.

Beginning with the 2004 issues, working papers are no longer available in print format. Instead they are distributed electronically. As each new paper is completed subscribers are notified by e-mail and a link to the paper is provided.

To subscribe to the Policy Research Division working paper e-mail notification list, or to obtain back issues from 1989 to 2003, please send your request to prdwp@popcouncil.org.

PDFs of recent issues are available at www.popcouncil.org/publications/wp/prd/rdwplist.html

2006

213 Paul Demeny and Geoffrey

McNicoll, "The political demography of the world system, 2000-2050."

212 Monica Grant and Kelly Hallman, "Pregnancy-related school dropout and prior school performance in South Africa."

211 Kelly Hallman, Sara Peracca, Jennifer Catino, and Marta Julia Ruiz, "Multiple disadvantages of Mayan females: The effect of gender, ethnicity, poverty, and residence on education in Guatemala."

210 Geoffrey McNicoll, "Policy lessons of the East Asian demographic transition."

209 Cynthia B. Lloyd, Cem Mete, and Monica J. Grant, "The implications of changing educational and family circumstances for children's grade progression in rural Pakistan: 1997-2004.”

\section{5}

208 James F. Phillips, Ayaga A. Bawah, and Fred N. Binka, "Accelerating reproductive and child health program development: The Navrongo Initiative in Ghana."

207 John Bongaarts and Griffith Feeney, "The quantum and tempo of life-cycle events."

206 Barbara S. Mensch, Monica J. Grant, and Ann K. Blanc, "The changing context of sexual initiation in sub-Saharan Africa."

205 Geoffrey McNicoll, "Population and sustainability."

204 John Bongaarts, "The causes of stalling fertility transitions."

203 Ayaga A. Bawah and Fred N. Binka, "How many years of life could be saved if malaria were eliminated from a hyperendemic area of northern Ghana?" 

marriage among men and women in the developing world."

201 Zachary Zimmer, "Active life expectancy and functional limitations among older Cambodians: Results from a 2004 survey."

200 Brian Wells Pence, Philomena Nyarko, James F. Phillips, and Cornelius Debpuur, "The effect of community nurses and health volunteers on child mortality: The Navrongo Community Health and Family Planning Project."

199 Zachary Zimmer, Linda G. Martin, Mary Beth Ofstedal, and Yi-Li Chuang, "Education of adult children and mortality of their elderly parents in Taiwan."

198 Mian Bazle Hossain, James F. Phillips, and Thomas K. LeGrand, "The impact of childhood mortality on fertility in six rural thanas of Bangladesh."

197 Kristine R. Baker, Mary Beth Ofstedal, Zachary Zimmer, Zhe Tang, and Yi-Li Chuang, "Reciprocal effects of health and economic well-being among older adults in Taiwan and Beijing."

196 Mark R. Montgomery and Paul C. Hewett, "Poverty and children's schooling in urban and rural Senegal."

2004

195 Luciana Suran, Sajeda Amin, Lopita Huq, and Kobita Chowdury, "Does dowry improve life for brides? A test of the bequest theory of dowry in rural Bangadesh."

194 Barbara S. Mensch, Monica J. Grant, Mary P. Sebastian, Paul C. Hewett, and Dale Huntington. "The effect of a livelihoods intervention in an urban slum in India: Do vocational counseling and training alter the attitudes and behavior of adolescent girls?"

193 Amanda Ritchie, Cynthia B. Lloyd, and Monica Grant. "Gender differences in time use among adolescents in developing countries: Implications of rising school enrollment rates."

192 John Bongaarts. "Long-range trends in adult mortality: Models and projection methods."

191 John Koku Awoonor-Williams, Ellie S. Feinglass, Rachel Tobey, Maya N. Vaughan-Smith, Frank K. Nyonator, Tanya C. Jones, and James F. Phillips, "Bridging the gap between evidence-based innovation and national healthsector reform in Ghana."

190 Kelly Hallman, "Socioeconomic disadvantage and unsafe sexual behaviors among young women and men in South Africa."

189 Toshiko Kaneda, Zachary Zimmer, and Zhe Tang, "Differentials in life expectancy and active life expectancy by socioeconomic status among older adults in Beijing." 
188 Cynthia B. Lloyd and Monica J.

Grant, "Growing up in Pakistan:

The separate experiences of males and females."

187 Zachary Zimmer, Xianghua Fang, Toshiko Kaneda, Zhe Tang, and Julia Kwong. "Trends and transitions in children's coresidence with older adults in Beijing municipality."

186 Sajeda Amin and Alaka M. Basu. "Popular perceptions of emerging influences on mortality and longevity in Bangladesh and West Bengal."

185 John Bongaarts. "Population aging and the rising cost of public pensions."

184 Mark R. Montgomery and Paul C. Hewett. "Urban poverty and health in developing countries: Household and neighborhood effects." 